\title{
Description of functioning in sickness certificates
}

\author{
Emma Nilsing, Elsy Söderberg, Helena Normelli and Birgitta Öberg
}

\section{Linköping University Post Print}

N.B.: When citing this work, cite the original article.

The final, definitive version of this paper has been published in:

Scandinavian Journal of Public Health, (39), 5, 508-516, 2011.

Emma Nilsing, Elsy Söderberg, Helena Normelli and Birgitta Öberg, Description of functioning in sickness certificates

http://dx.doi.org/10.1177/1403494811399954

by SAGE Publications Ltd, All rights reserved.

http://www.uk.sagepub.com/

Postprint available at: Linköping University Electronic Press

http://urn.kb.se/resolve?urn=urn:nbn:se:liu:diva-69815 


\section{Description of functioning in sickness certificates}

Authors: Emma Nilsing¹, Elsy Söderberg², Helena Normelli ${ }^{3}$, Birgitta Öberg1

${ }^{1}$ Division of Physiotherapy, ${ }^{2}$ Division of Community Medicine

Department of Medical and Health Sciences

Linköping University, Sweden

${ }^{3}$ Orthopaedic Centre

Linköping University Hospital, Sweden

Correspondence: Emma Nilsing, Division of Physiotherapy, Department of Medical and Health sciences, Linköping University, SE-581 83 Linköping, Sweden

Phone no. +46101037805

E-mail: emma.nilsing@liu.se 


\section{Abstract}

Aims. Sickness certificates are to provide information on a disease and its consequences on the patient's functioning. This information has implications for the patient's rights to sickness benefits and return to work measures. The objective of this study was to investigate the description of functioning in sickness certificates according to WHO's International Classification of Functioning, Disability, and Health (ICF), and to describe the influence of patients' age, gender, diagnostic group, and affiliation of certifying physician. Method. A content analysis of written statements regarding how the disease limits the patient's functioning with ICF as a framework was performed in 475 sickness certificates, consecutively collected in Östergötland County, Sweden. Results. Musculoskeletal diseases (MSD) were the largest diagnostic group, followed by mental disorders (MD). Certificates were mainly issued from physicians at hospitals and in primary health care (PHC). ICF was applicable for classifying statements regarding functioning in 311 certificates $(65 \%)$. The distribution of components was $58 \%$ body functions, $26 \%$ activity, and $7 \%$ participation. The descriptions were primarily restricted to the use of at least one component; namely, body functions. Sub group analysis showed that descriptions of activity and participation were more common in certificates for MD and MSD, or those issued by PHC physicians. A multiple regression analysis with the activity component as dependent variable confirmed the results by showing that activity was related to both diagnosis and affiliation. Conclusions. In a consecutive sample of sickness certificates it was shown that information on functioning is scarce. When functioning was described, it was mainly body oriented.

Key words: sick leave, physicians' assessment of work capacity, musculoskeletal diseases, mental disorders, International Classification of Functioning, Disability, and Health 


\section{Introduction}

Sick leave represents in many European countries a public health problem that extends over several structural levels including society, workplace and the affected individual [1].

European social security systems are based on similar principles and struggle with sick leave due to similar conditions, such as mental and musculoskeletal disorders, often with limited evidence of objective disease or impairment $[1,2]$. In most European countries, physicians are responsible for certifying sick leave due to a disease or injury and its consequences on patients' functioning and work ability [3]. Sickness certification is one of physicians' most important tasks [3], although described as problematic especially when there are no objective clinical findings [3-5]. A related identified problem is to handle the different roles as patient advocate, medical expert and gatekeeper $[3,4,6]$. When deciding on sickness certification, the doctor-patient relationship sometimes outweighs the responsibility to the social insurance system [4], which could lead to sick leave on incorrect basis.

Studies including physicians in primary health care $[4,7,8]$ and with different specialities $[6$, 9] have shown that physicians face challenges in assessing the patient's functioning and work ability, and to issue the need for sickness certification. Since prolonged disability and sick leave reduces the probability of return to work, the patients' functioning need be assessed as soon as possible $[2,10,11]$. According to the Swedish National Insurance Act, a person is entitled to sickness benefits if she/he has (a) a disease or injury with (b) consequences on functioning, which in relation to the demands at work (c) impairs the work ability. This information is provided by physicians in sickness certificates and the formal decision is then made by the social insurance office [1]. However, a large proportion of sickness certificates do not include enough information for a decision, especially with regard to how the disease limits the patient's functioning [12]. The importance of this information is emphasised by its 
implications for assuring patients' right to sickness benefits and appropriate return to work measures [3].

To gain deeper understanding in sickness-certification research WHO's International Classification of Functioning, Disability, and Health (ICF) can be used to classify and categorise functioning as a complement to the diagnostic classification ICD-10 [13]. ICF offers a worldwide consensus on key concepts describing human functioning and the consequences of health problems on body function/structure, activity, and participation, along with influences from environmental factors (Figure 1). Functioning is an umbrella term for body function/structure, activity, and participation, and disability serves as an umbrella term for impairment, activity limitation, and participation restriction [13].

[Insert figure 1 about here]

To the best of our knowledge, thus far, two studies have used ICF in sickness-certification research $[14,15]$. One study proposed ICF core sets for functional assessments in disability claims, with an emphasis on activity/participation [14]. An interview study with social insurance physicians considered participation to be the most important factor [15]. Physicians affiliated to different clinics meet different patients, and factors related to the patient/and or the physician might influence the assessment of functioning and work ability $[3,12,16]$. Further, there is a lack of consensus regarding how functioning should be assessed [3], and there is little scientific knowledge about which aspects physicians actually consider when assessing patients' functioning and work ability in sickness-certification practice.

\section{Aim}


The objective of this study was to investigate the description of functioning in sickness certificates according to ICF, and to describe the influence of patients' age, gender, diagnostic group, and affiliation of the certifying physician.

\section{Methods}

\section{Study setting and sample}

A consecutive collection of all the sickness certificates in a new sick-leave period delivered to the insurance offices in Östergötland County, Sweden, was performed during two weeks in September 2007. This procedure to collect data from sickness certificates has been used previously [12]. The sample does not include the first seven days due to patient's selfcertification. By the time of the data collection, there were no time-lines for review of eligibility or maximum length of sick leave in Sweden. The consecutive collection resulted in 497 certificates. After excluding 16 certificates which were not certifying a new sick-leave period, because of death $(n=4)$ or incorrect personal number $(n=2), 475$ new certificates were included in the analysis.

Information collected from the sickness certificates included the following aspects: affiliation of the certifying physician (primary health care, PHC; occupational health service, OHS; hospital; private clinic), patient's age $(\leq 24,25-34,35-44,45-54, \geq 55)$, gender, main diagnosis as cause to the sick leave coded according to ICD-10, and certified part-time sick leave (yes/no). A categorisation of the ICD-10 codes was performed: F into mental disorders (MD), M into musculoskeletal diseases (MSD), I and J into Cardio-respiratory diseases (CR), and the remaining codes (A-E, G, H, K, L, N-Z) into “Other” Diagnoses. This categorisation has 
been used previously $[1,17]$, but in this study respiratory and cardiovascular diseases were categorised as one category.

\section{Content analysis}

The text on the description of the patient's functioning written by physicians in sickness certificates was analysed using content analysis $[18,19]$ with ICF as a theoretical framework [13]. The current study follows the steps of analysis as originally described by DowneWamboldt [19]. The text provided on the question "How does the disease limit the patient's ability/activity?" was selected as the unit of analysis. The text was read and meaningful concepts were identified and linked to the different components of ICF: body functions/structures, activities, participation, and environmental factors [13, 20]. An operational distinction between activity and participation was performed. The domains "major life areas" and "community, social, and civic life" were designated as components of participation, and the remaining domains were designated as components of activity. Categories are presented on the first hierarchical level of system of the ICF classification, i.e. the components. Insufficient text, such as "operated", "rest", or no information given at all, was assigned to a separate category, "no description" [20]. The following text unit serves as an illustration of the process: "the patient has low back pain and cannot lift". In this text two meaningful concepts were identified and linked to different ICF components:

Concept I: low back pain linked to Pain in back (code b28013) in body functions.

Concept II: lift linked to Lifting and carrying objects (code d430) in activities.

The same procedure was used to analyse the text that was written in response to the questions "anamnesis" and "clinical findings". 
All the researchers in this study had experience with using ICF. Before the question on functioning was analysed and classified according to ICF, the researchers' preconceptions were declared and a mutual understanding of the analysis and ICF classification was attained. An independent analysis of the free text into the classification was performed by researcher one (EN) for all certificates $(n=475)$, and was repeated by researcher two (HN) for 226 certificates (48\%). The ambiguities and disagreements were solved in consensus meetings between the two researchers and the adjudicator (BÖ). The text regarding functioning was classified into groups of categories (body; activity; participation; environmental factors; no description) on which statistical analysis was performed [18, 19].

\section{Statistical analysis}

Pearson's chi square test or Fisher's exact test were used to analyse association between two categorical/nominal variables. Bonferroni adjustment was used for multiple comparisons. Student's t-test and one-way ANOVA with Bonferroni post hoc test were used for group comparisons of normally distributed interval scale variables. Differences were considered significant at $p<0.05$. A multiple logistic regression analysis with the dependent variable "activity component" was conducted to assess the relationship between the dichotomous outcome and several independent variables. Activity was chosen due to its central importance in sickness certificates as the answer to the question in the certificate "how does the disease limit the patient's ability/activity [3], in work ability assessments [21, 22], and in ICF [13].

\section{Ethical considerations}

The study was approved by the Research Ethics Committee of the Faculty of Health Sciences of Linköping University, Sweden. 


\section{Results}

As presented in table I, MSD was the largest diagnostic group $(n=137)$, followed by MD $(n=80)$. Within the diagnostic group "Other" Diagnoses, injuries $(n=58)$, and pregnancyrelated disorders $(n=27)$ were most common. Patients were in mean 45 years old (SD 12.5). The majority of the certificates were issued for women $(n=293)$. Certificates were issued mainly from physicians at hospitals $(n=206)$ and in PHC $(n=201)$, and, to a lesser extent, from OHS ( $n=24)$ and private clinics $(n=39)$. The proportions of MD and MSD varied from $8 \%$ to $42 \%$ respectively from $13 \%$ to $41 \%$ depending on the particular affiliation, being more frequent in PHC and OHS. The mean number of certified sick-leave days was 31 (SD 29), more days for men than women $(p=0.032)$.

[Insert table I about here]

\section{Description of functioning analysed with ICF}

All of the analysed texts on functioning included a variety of amount of words, from no word at all to several sentences. The percentage of agreement between the two researchers was $78 \%$ (177/226). The agreement achieved $92 \%$ after consensus discussions of the items "move" ( $n=5$, all classified into no description), "not use the hand" ( $n=8$, six classified into no description and two into activity), "focusing" ( $n=6$, four classified into body and two into activity), and information on work ( $n=12$, ten classified into participation and two into no description). Remaining disagreements $(n=18)$, with items varying from "can barely lift the arm", "not in the shape for seeking employment" to "cannot work", were solved in the consensus meeting and much discussion to reach consensus was not needed. The final 
classification in proposed categories was even distributed between the two researchers. The linking process extended for several of months and included checks of accuracy of coding.

In 311 certificates (65\%), a description of the patient's functioning was applicable to ICF, and could be classified according to at least one of the components (Table II). There were differences with regard to affiliation of physician and diagnostic group, but not to patient's age or gender. Text on functioning was completely missing in 21 certificates. In 143 certificates, the information was insufficient for ICF classification. Environmental factors were stated in only a few certificates.

[Insert table II about here]

In almost all groups at least one ICF component describing functioning was primarily used, most often in certificates with MD (81\%) and MSD (72\%) compared with "Other" Diagnoses (55\%). At least one component was also more common in certificates issued from PHC physicians (78\%) and OHS (88\%) than from hospitals (54\%) or private clinics (46\%).

The description of functioning was mainly provided on the component of the body $(n=276$, $58 \%)$, and to a lesser extent on activity $(n=125,26 \%)$ and participation $(n=31,7 \%)$. When information collected from anamnesis and clinical findings was integrated in the analysis, the distribution of components increased to $92 \%$ body functions $(n=432), 35 \%$ activity $(n=168)$, and $12 \%$ participation $(n=59)$. Pain, sleep, anxiety, attention are typical examples of descriptions of functioning linked to body functions. Handling stress, standing, lifting and carrying, are common examples linked to activity, and type of work to participation. 
As presented in table III, certificates issued for "Other" Diagnoses provided significant less information on functioning according to the ICF components body (49\%), activity (14\%), and participation (3\%) compared with certificates issued for MD (76\%, 43\% and $11 \%$ respectively). The components activity and participation were less common in certificates issued for "Other" Diagnoses than those for MSD. The differences between certificates issued for "Other" Diagnoses and MD or MSD remained when adding information collected from anamnesis and clinical findings.

Physicians at hospitals provided significant scarce information on functioning according to the components body (48\%), activity (17\%), and participation (2\%) compared with PHC physicians $(70 \%, 37 \%$ and $10 \%$ respectively), even when including information collected from anamnesis and clinical findings (table III).

A multiple logistic regression model on description of functioning according to the component of activity collected from anamnesis, clinical findings and the question "how does the disease limit the patient's ability/activity" revealed similar results. As shown in table IV, the description was related to diagnosis and affiliation.

[Insert table III and IV about here]

\section{Discussion}

The main finding of this study indicates that sickness certificates provide scarce information on functioning. The descriptions of functioning were primarily on the component of the body. Certificates with MD and MSD diagnoses, or those issued from PHC physicians put more emphasis on activity/participation-oriented descriptions of functioning and the use of at least one ICF component compared with other groups. 
As reflected in models on work ability, not only biomedical aspects are sufficient for explaining work ability and sick leave [21,23]. Ilmarinen defines work ability as a process of human resources in relation to work. Human resources can be described by (1) health and functional capacities, (2) education and competence, (3) values and attitudes, and (4) motivation. When these individual factors are related to (5) work demands, (6) work community and management, and (7) work environment, the outcome can be called individual work ability [21]. The model of illness flexibility by Johansson and Lundberg [23] explains sick leave, but includes work ability which is determined by loss of function and work conditions. Work conditions are differently described in these models, and the illness flexibility model does not include values, attitudes or motivation [23]. Information provided in sickness certificates on disease and the consequences on functioning corresponds to the dimensions on health and functional capacities as described by Ilmarinen and the loss of function described by Johansson [21,23]. Sickness certificates shall include work demands and type of work, but other work conditions or human resources such as motivation are not requested. In the certificate, the physician has to provide information on diagnosis, its consequences on functioning, and in relation to work the work ability [3]. Functioning and work ability are sometimes used synonymously in the literature [3], although functioning, physical and psychological, is identified as one of the important factors contributing to work ability [21-23]. The ICF was chosen as a framework for this study. ICF is a classification system based on a biopsychosocial model, but it is not regarded as a theoretical model. According to ICF, functioning is conceptualised as consequences of complex interactions between the individual and the society [13]. We used ICF since the classification complements the diagnostic classification ICD-10 and offers a comprehensive list of categories relevant for the description of functioning in sickness-certification practice. ICF 
core sets for sick leave is yet to be developed; however, core sets for functional assessment in disability claims has been proposed [14]. The authors suggested 20 categories for the core sets: $25 \%$ from body functions and $75 \%$ from activities and participation. These proportions are in contrast with our findings, in which the body predominated, comprising $58 \%$ of the categories. In our study, environmental factors were seldom described, which is in accordance with previous studies $[14,15]$. According to social insurance physicians who were interviewed about how they determined work ability [15], participation was considered to be most important, especially for those patients with MD, followed by body functions/structures for patients with MSD. The type of disease was most important for prognosis of work ability in the short and long term [15]. In a focus group study, PHC physicians conceptualised functioning as a physical, mental, and social ability, but in clinical practice they emphasised physical ability [24]. The results in our study show that the component of the body was dominating in the total certificates. However, certificates with MSD and MD or those issued from PHC physicians provided more often a description of functioning according to activity/participation components compared with other groups. Diagnosis and physician affiliation are related to each other, probably mainly due to differences in patient categories visiting the various affiliations. Nevertheless, these results emphasise that the description of functioning is related to both diagnosis and physician affiliation. This finding was confirmed in a logistic regression analysis on the description of functioning according to the activity component. Our results and findings from earlier research on physicians' sicknesscertification practice regarding quality in certificates [12], certification of sick leave [16] and experiences of certification as problematic $[3,7-9,25]$, imply that there may be a need for interventions to reduce these variations and to increase the quality in sickness certificates. The results from a survey by Löfgren et al. [26] including physicians with different specialities suggested that the low quality in sickness certificates may not be explained by the need for 
more knowledge or skills in filling out sickness certificates. Although, the physicians in the survey stated that they needed more knowledge and skills in handling sickness certification, for example regarding how to assess work ability [26]. Future studies need to investigate whether the lack of knowledge or skills to assess work ability is reflected in the descriptions of functioning provided in sickness certificates, or if the low quality in certificates is caused by other factors such as lack of resources .

Our results imply that diagnosis also appears to have an influence on the description of functioning in sickness certificates. These results may relate to the strong association found between MD, but also MSD, and impaired work ability [17]. Further, since some MSD and MD, mostly seen in PHC and OHS, are ambiguity diagnoses without objective clinical findings [1,2], the physician may use more than medical information when describing functioning and certifying sick leave $[4,12,27,28]$. The decision making is crucial for the eligibility for sickness benefits in view of the fact that sickness certificates should provide information on the disease and its consequences on the patient's functioning, which in relation to the demands at work impair the work ability. This implies at least a description on activity/participation. Since about one third of the certificates lacked a description of functioning and the remaining majority was on the component of the body, the basis is assumed insufficient for decisions on sickness benefits. By elucidate the description of functioning according to the ICF, our results enhance previous research regarding the quality of sickness certificates [12]. This situation may lead to inefficient administration, inaccurate decisions on benefits and return to work measures, as well as increased workload for the health care when the physician has to adjust the insufficient certification. More attention to all the factors related to work ability may be needed in the sickness-certification practice to clarify the relationship between disease and impaired work ability, to make correct 
assessments by distinguishing between those patients who can work and those who cannot, and to address the obstacles for return to work early in the sick leave. In this context, ICF can be used as a tool for examining the many facets of health and functioning.

Strengths of this study are that it includes all certificates that the social insurance office in Östergötland County, Sweden, received during the study period, and that this procedure to collect data from sickness certificates has previously been proved to be useful [12].

Furthermore, the sample size was expected with regard to the trend of decreasing new sickleave spells [29] and the distribution of the diagnostic group was considered to be representative regarding causes to sick leave $[1,2,12]$. This study has a number of limitations that need to be addressed. First, all the variables were collected from certificates and as a consequence the analyses are restricted to information provided in these certificates. More information may for example be written in the patients' records, but we did not have access to those. Secondly, the diagnostic group "Other" is a heterogeneous group consisting of a wide range of different diagnoses. Further, CR diseases, OHS and private clinics are groups based on small sample sizes. These certificates were included in the analyses since the main aim was to investigate the description of functioning in all certificates issued during the sample period. However, the results based on these sub groups should be interpreted with caution. Thirdly, we included information on functioning written in sickness certificates and linked meaningful concepts to the ICF, which limits the findings to how functioning is conceptualised in the ICF. We found an inter-rater agreement in the classification of $78 \%$. The majority of the disagreements dealt with concepts with multiple meanings difficult to link to the most precise ICF category. The disagreements may though have been reduced by the systematic way to analyse and describe data conducted with content analysis [19] and linkage to ICF [20], which also has been used in previous studies [18, 30, 31]. However, the 
ambiguities found in this study indicate a need for reliable coding scheme and confirm previous suggestion that reliability should always be examined when applying ICF [20]. Finally, since we analysed information written in sickness certificates the findings cannot be generalised to how functioning is assessed in clinical practice, only to how functioning is described in sickness certificates.

\section{Conclusions}

In a consecutive sample of sickness certificates it was shown that information on functioning is scarce. Future research is needed to further investigate if this is valid in other samples of certificates, if more comprehensive descriptions of functioning improve patients' rights to benefits, or secure that patients receive appropriate interventions.

\section{Funding}

This study was funded by the National Social Insurance Administration and the County Council in Östergötland, Sweden (grant number HIS 7/0728).

\section{Conflicts of interest}

None. 


\section{References}

[1] Alexanderson K, Norlund A. Swedish Council on Technology Assessment in Health Care (SBU). Chapter 1. Aim, background, key concepts, regulations, and current statistics. Scand J Public Health Suppl 2004;63:12-30.

[2] Waddell G, Burton AK. Concepts of rehabilitation for the management of common health problems. London: TSO 2004.

[3] Wahlstrom R, Alexanderson K. Swedish Council on Technology Assessment in Health Care (SBU). Chapter 11. Physicians' sick-listing practices. Scand J Public Health Suppl 2004;63:222-55.

[4] Hussey S, Hoddinott P, Wilson P, Dowell J, Barbour R. Sickness certification system in the United Kingdom: qualitative study of views of general practitioners in Scotland. Bmj 2004 Jan 10;328(7431):88.

[5] Norrmen G, Svardsudd K, Andersson DK. How primary health care physicians make sick listing decisions: The impact of medical factors and functioning. BMC Fam Pract 2008 Jan 21;9(1):3.

[6] von Knorring M, Sundberg L, Lofgren A, Alexanderson K. Problems in sickness certification of patients: A qualitative study on views of 26 physicians in Sweden. Scand J Prim Health Care 2008 Mar;26(1):22-8.

[7] Gulbrandsen P, Hofoss D, Nylenna M, Saltyte-Benth J, Aasland OG. General practitioners' relationship to sickness certification. Scand J Prim Health Care 2007 Mar;25(1):20-6.

[8] Swartling M, Peterson S, Wahlstrom R. Views on sick-listing practice among Swedish General Practitioners--a phenomenographic study. BMC Fam Pract 2007;8:44.

[9] Lofgren A, Hagberg J, Arrelov B, Ponzer S, Alexanderson K. Frequency and nature of problems associated with sickness certification tasks: A cross-sectional questionnaire study of 5455 physicians. Scand J Prim Health Care 2007 Sep;25(3):178-85.

[10] Stucki G, Stier-Jarmer M, Grill E, Melvin J. Rationale and principles of early rehabilitation care after an acute injury or illness. Disabil Rehabil 2005 Apr 8-22;27(7-8):3539.

[11] Airaksinen O, Brox JI, Cedraschi C, Hildebrandt J, Klaber-Moffett J, Kovacs F, et al. Chapter 4. European guidelines for the management of chronic nonspecific low back pain. Eur Spine J 2006 Mar;15 Suppl 2:S192-300.

[12] Soderberg E, Alexanderson K. Sickness certificates as a basis for decisions regarding entitlement to sickness insurance benefits. Scand J Public Health 2005;33(4):314-20.

[13] World Health Organization, ed. ICF - International classification of functioning, disability and health. Genève: World Health Organization 2001.

[14] Brage S, Donceel P, Falez F. Development of ICF core set for disability evaluation in social security. Disabil Rehabil 2008;30(18):1392-6.

[15] Slebus FG, Sluiter JK, Kuijer PP, Willems JH, Frings-Dresen MH. Work-ability evaluation: a piece of cake or a hard nut to crack? Disabil Rehabil 2007 Aug 30;29(16):1295300.

[16] Englund L, Tibblin G, Svardsudd K. Variations in sick-listing practice among male and female physicians of different specialities based on case vignettes. Scand J Prim Health Care 2000 Mar;18(1):48-52.

[17] Martimo KP, Varonen H, Husman K, Viikari-Juntura E. Factors associated with selfassessed work ability. Occup Med (Lond) 2007 Aug;57(5):380-2.

[18] Cavanagh S. Content analysis: concepts, methods and applications. Nurse research 1997;40(3):5-16. 
[19] Downe-Wamboldt B. Content analysis: method, applications, and issues. Health Care Women Int 1992 Jul-Sep;13(3):313-21.

[20] Cieza A, Geyh S, Chatterji S, Kostanjsek N, Ustun B, Stucki G. ICF linking rules: an update based on lessons learned. J Rehabil Med 2005 Jul;37(4):212-8.

[21] Ilmarinen JE. Aging workers. Occup Environ Med 2001 Aug;58(8):546-52.

[22] Fadyl JK, McPherson KM, Schluter PJ, Turner-Stokes L. Factors contributing to workability for injured workers: literature review and comparison with available measures. Disabil Rehabil 2010;32(14):1173-83.

[23] Johansson G, Lundberg I. Adjustment latitude and attendance requirements as determinants of sickness absence or attendance. Empirical tests of the illness flexibility model. Soc Sci Med 2004 May;58(10):1857-68.

[24] Krohne K, Brage S. How GPs in Norway conceptualise functional ability: a focus group study. Br J Gen Pract 2008 Dec;58(557):850-5.

[25] Swartling M, Wahlstrom R. Isolated specialist or system integrated physician--different views on sickness certification among orthopaedic surgeons: an interview study. BMC Health Serv Res 2008;8:273.

[26] Lofgren A, Hagberg J, Alexanderson K. What physicians want to learn about sickness certification: analyses of questionnaire data from 4019 physicians. BMC Public Health 2010;10:61.

[27] Meershoek A, Krumeich A, Vos R. Judging without criteria? Sickness certification in Dutch disability schemes. Sociol Health Illn 2007 May;29(4):497-514.

[28] Cohen DA, Aylward M, Rollnick S. Inside the fitness for work consultation: a qualitative study. Occup Med (Lond) 2009 Aug;59(5):347-52.

[29] The Swedish Social Insurance Agency. Social insurance in figures 2008. [cited 2010 Jan 10]; Available from: www.forsakringskassan.se

[30] Escorpizo R, Cieza A, Beaton D, Boonen A. Content comparison of worker productivity questionnaires in arthritis and musculoskeletal conditions using the International

Classification of Functioning, Disability, and Health framework. J Occup Rehabil 2009 Dec;19(4):382-97.

[31] Noonan VK, Kopec JA, Noreau L, Singer J, Chan A, Masse LC, et al. Comparing the content of participation instruments using the international classification of functioning, disability and health. Health Qual Life Outcomes 2009;7:93. 


\section{Tables and figures}

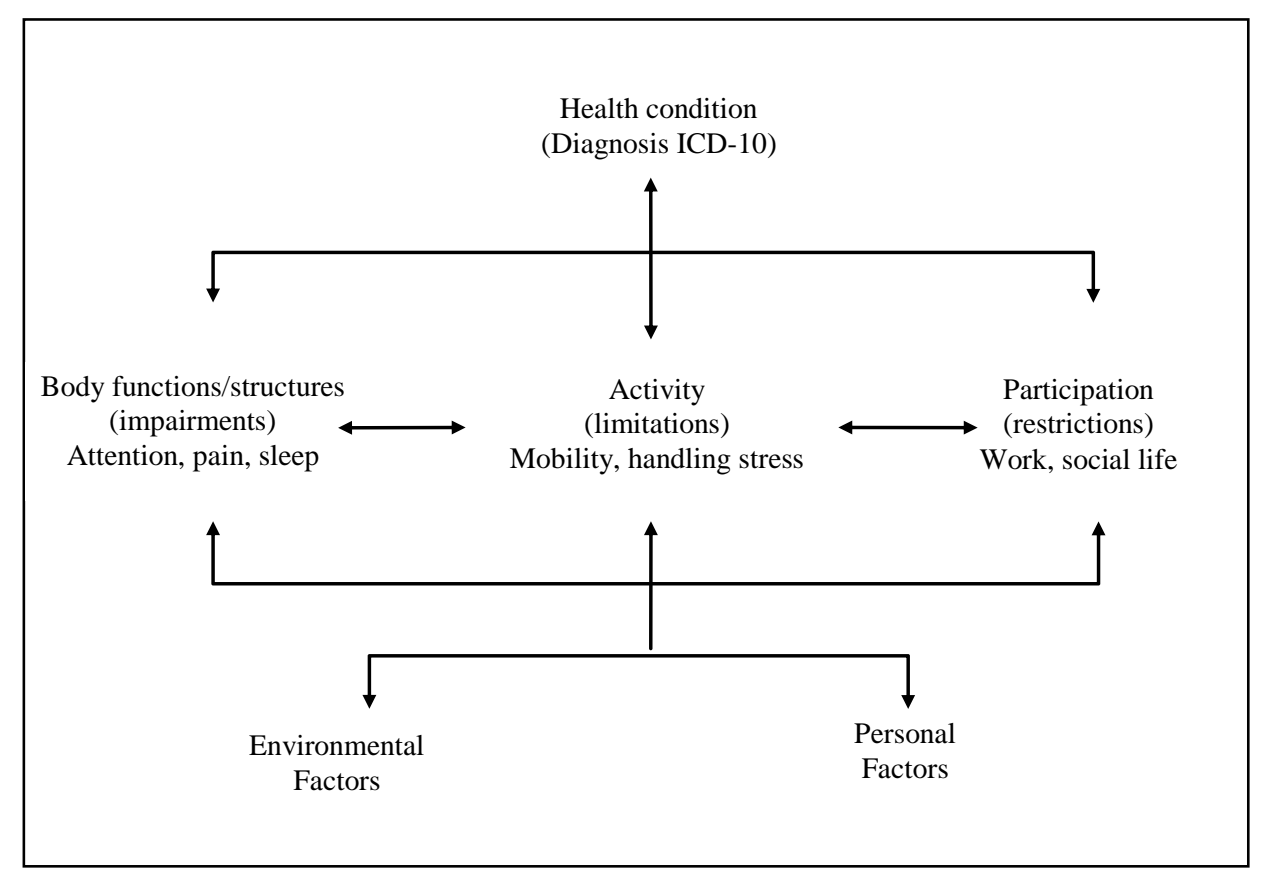

Figure I. Interactions among ICF components 
Table I. Information given in sickness certificates on certified part-time sick leave, sick-leave length and age of the patient cross tabulated by gender, diagnostic group,

affiliation of certifying physician

\begin{tabular}{|c|c|c|c|c|c|c|c|}
\hline & $\begin{array}{l}\text { Total } \\
\%(\mathrm{n})\end{array}$ & $\begin{array}{c}\text { Part-time sick } \\
\text { leave \% (n) }\end{array}$ & $P$ value & $\begin{array}{c}\text { Days on sick } \\
\text { leave } \\
\text { mean (SD) }\end{array}$ & $P$ value & $\begin{array}{l}\text { Patient age } \\
\text { mean }(\mathrm{SD})\end{array}$ & $P$ value \\
\hline \multicolumn{8}{|c|}{ Patient gender $(n=475)$} \\
\hline Women & $62(293)$ & $16(46)$ & $\mathrm{W}>\mathrm{M} 0.011$ & $29(26.5)$ & & $44(12.2)$ & \\
\hline Men & $38(182)$ & $8(14)$ & & $34(32.9)$ & $\mathrm{M}>\mathrm{W} 0.032$ & $46(12.8)$ & \\
\hline \multicolumn{8}{|c|}{ Diagnostic group $(n=470)$} \\
\hline MD & $17(80)$ & $16(13)$ & & $35(31.0)$ & & $41(12.1)$ & \\
\hline MSD & $29(137)$ & $15(20)$ & & $31(28.2)$ & & $48(11.8)$ & MSD $>$ MD $<0.001$, MSD $>$ Other 0.012 \\
\hline $\mathrm{CR}$ & $9(42)$ & $7(3)$ & & $26(29.3)$ & & $49(12.5)$ & $\mathrm{CR}>\mathrm{MD} 0.003$ \\
\hline Other & $45(211)$ & $11(24)$ & & $30(29.4)$ & & $43(12.3)$ & \\
\hline \multicolumn{8}{|c|}{ Affiliation of physician $(n=470)$} \\
\hline PHC & $43(201)$ & $19(38)$ & $\mathrm{PHC}>\mathrm{H}<0.001$ & $21(19.4)$ & & $44(13.0)$ & \\
\hline OHS & $5(24)$ & $25(6)$ & OHS>H $0.007 *$ & $25(15.8)$ & & $49(9.7)$ & \\
\hline Hospital $(\mathrm{H})$ & $44(206)$ & $6(13)$ & & $39(35.0)$ & $\mathrm{H}>\mathrm{PHC}<0.001$ & $44(11.9)$ & \\
\hline Private $(\mathrm{P})$ & $8(39)$ & $8(3)$ & & $37(27.9)$ & $\mathrm{P}>\mathrm{PHC} 0.006$ & 45 (13.6) & \\
\hline
\end{tabular}

MD, mental disorders; MSD, musculoskeletal diseases; CR, cardio-respiratory diseases; O, Other Diagnoses; PHC, primary health care; OHS, occupational health services;

Private, private clinics. *Fisher's exact test. 
Table II. Information provided in sickness certificates on functioning, classified into the components of ICF

\begin{tabular}{lcc}
\hline ICF component & $\mathrm{n}$ & $\%$ \\
\hline No description & 165 & 35 \\
Body & 177 & 37 \\
Activity & 30 & 6 \\
Participation & 2 & 0,4 \\
Body and Activity & 73 & 15 \\
Body and Participation & 7 & 2 \\
Activity and Participation & 3 & 0,6 \\
Body and Activity and & 19 & 4 \\
Participation & & \\
Total & 475 & 100 \\
\hline
\end{tabular}

Functioning refers to the question in the certificate "how does the disease limit the patient's ability/activity". 
Table III. Proportions $(\%)$ and number $(n)$ of descriptions of functioning collected from different parts of sickness certificates, classified according to the different components of ICF and cross tabulated by diagnostic group and affiliation of certifying physician.

\begin{tabular}{|c|c|c|c|c|c|c|}
\hline & & \multicolumn{5}{|c|}{ Diagnostic group } \\
\hline & & $\operatorname{MD}(n=80)$ & $\operatorname{MSD}(n=137)$ & $\mathrm{CR}(n=42)$ & Other $(n=211)$ & $P$ value \\
\hline ICF component & Part of the certificate & & & & & \\
\hline \multirow[t]{4}{*}{ Body \% (n) } & Functioning & $76(61)$ & $60(82)$ & $67(28)$ & $49(104)$ & $\mathrm{MD}>\mathrm{O}<0.001$ \\
\hline & Anamnesis & $89(71)$ & $80(101)$ & $95(40)$ & $78(165)$ & \\
\hline & Clinical findings & $90(72)$ & $80(110)$ & $86(36)$ & $64(135)$ & \\
\hline & Total & $100(80)$ & $91(125)$ & $98(41)$ & $90(189)$ & $\mathrm{MD}>\mathrm{O}$ 0.003, MD>MSD 0.004* \\
\hline \multirow[t]{4}{*}{ Activity \% (n) } & Functioning & $43(34)$ & $43(59)$ & $5(2)$ & $14(30)$ & $\mathrm{MD}, \mathrm{MSD}>\mathrm{CR}, \mathrm{O}<0.001$ \\
\hline & Anamnesis & $30(24)$ & $20(27)$ & $5(2)$ & $10(20)$ & \\
\hline & Clinical findings & $11(9)$ & $7(10)$ & $5(2)$ & $2(5)$ & \\
\hline & Total & $60(48)$ & $54(74)$ & $12(5)$ & $19(41)$ & $\mathrm{MD}, \mathrm{MSD}>\mathrm{CR}, \mathrm{O}<0.001$ \\
\hline \multirow[t]{5}{*}{ Participation \% (n) } & Functioning & $11(9)$ & $12(16)$ & $0(0)$ & $3(6)$ & MSD>O 0.001 \\
\hline & & & & & & $\mathrm{MD}>\mathrm{O} 0.007 *$ \\
\hline & Anamnesis & $10(8)$ & $11(15)$ & $2(5)$ & $4(8)$ & \\
\hline & Clinical findings & $0(0)$ & $2(2)$ & $0(0)$ & $1(1)$ & \\
\hline & Total & $20(16)$ & $20(27)$ & $5(2)$ & $7(14)$ & $\mathrm{MD}>\mathrm{O} 0.001, \mathrm{MSD}>\mathrm{O}<0.001$ \\
\hline
\end{tabular}




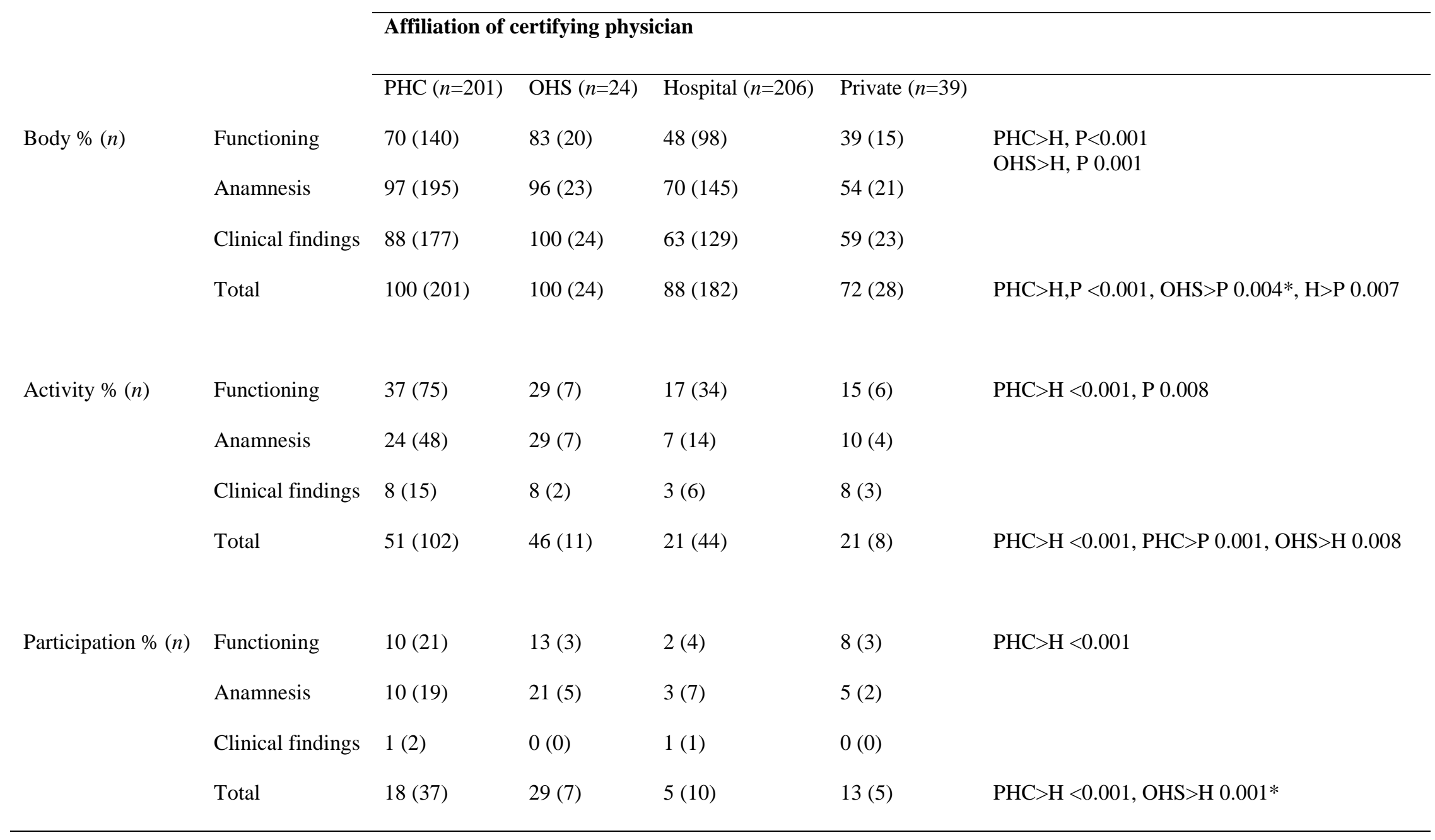

Chi square tests, except for *Fisher's exact test. $P<0.0083$ due to Bonferroni correction. MD, Mental disorders; MSD, musculoskeletal disorders; CR, cardio respiratory diseases; O, Other Diagnoses. Functioning refers to the question in the certificate "how does the disease limit the patient's ability/activity". Total = information collected from the questions anamnesis, clinical findings and functioning. Some certificates provided a description of more than one component. 
Table IV. Logistic regression analysis, method enter, with the dependent variable description of functioning classified according to the ICF component activity.

\begin{tabular}{|c|c|c|c|c|c|}
\hline Independent variable & B-Coefficient & Wald & $\mathrm{df}$ & $\mathrm{OR}(\mathrm{CI})$ & $\mathrm{P}$ \\
\hline Gender & & & 1 & & \\
\hline Women & 0.4 & 2.6 & & $1.5(0.9-2.3)$ & \\
\hline Age & & & 4 & & \\
\hline$\leq 24$ & 0.4 & 0.7 & & $1.5(0.6-4.1)$ & \\
\hline $25-34$ & -0.9 & 7.1 & & $0.4(0.2-0.8)$ & 0.008 \\
\hline $35-44$ & -0.3 & 1.2 & & $0.7(0.4-1.3)$ & \\
\hline $45-54$ & -0.5 & 2.9 & & $0.6(0.3-1.0)$ & \\
\hline$\geq 55$ & & & & 1 & \\
\hline Affiliation & & & 3 & & \\
\hline PHC & 0.9 & 11.8 & & $2.4(1.4-3.9)$ & 0.001 \\
\hline OHS & 0.5 & 0.9 & & $1.6(0.6-4.3)$ & \\
\hline Private & -0.4 & 0.9 & & $0.6(0.3-1.6)$ & \\
\hline Hospital & & & & 1 & \\
\hline Diagnosis & & & 3 & & \\
\hline MD & 1.7 & 30.3 & & $5.7(3.1-10.6)$ & $<0.001$ \\
\hline MSD & 1.3 & 22.9 & & $3.8(2.2-6.5)$ & $<0.001$ \\
\hline $\mathrm{CR}$ & -0.9 & 3.0 & & $0.4(0.1-1.1)$ & \\
\hline Other & & & & 1 & \\
\hline
\end{tabular}

$\mathrm{N}=465 . \mathrm{NRS}=29 \%$. Overall percentage correct predicted 73.5. Information on functioning is collected from anamnesis, clinical findings and the question "how does the disease limit the patient's ability/activity". MD, Mental disorders; MSD, musculoskeletal disorders; CR, cardio respiratory diseases; O, Other Diagnoses. 